\title{
New University: liberal education and arts in Brazil
}

\author{
Nathan Tejada de Podestá ${ }^{1}$, Silvia Maria Pires Cabrera Berg ${ }^{2}$ \\ ${ }^{1}$ Department of Music, University of São Paulo, Brazil, ${ }^{2}$ Department of Music, University of \\ São Paulo, Brazil.
}

\begin{abstract}
This paper is part of an ongoing research on the issue of music education in Brazilian universities. It aims to identify educational models that structure pedagogical practice at this level of studies. It distinguishes the types of professional and human education promoted in each one of the presented models (French, German and American) as well as liberal education, identified as a global trend. Relating the current socio-cultural political and economic context with education with the support of Godwin (2015), Berg (2012) and Jansen (1999) we argue that liberal education provides a structure that can favor the development of competences and skills demanded on the current conjuncture. In this frame, we will analyze, with the support of Paula (2008) and Santos \& Filho (2008), the historical dynamics of Brazilian higher education and show how liberal education and post-colonial philosophy is restructuring Brazilian universities. This "new university" allows the implementation of a multicultural, multi-epistemic pedagogy that overcome fragmentary disciplinary views and renders feasible the proposition of new ways of conceiving training, studying, teaching and research in music and arts.

Keywords: Higher Education; Educational Models; Liberal Education; Brazilian University; Music and Arts.
\end{abstract}




\section{Liberal education}

Based on the analysis of the Global Liberal Education Inventory (GLEI), a catalogue about liberal education programs located outside the United States, Godwin (2015) provides an initial profile about the emergency of liberal education, highlighting where, when and in what formats liberal education is emerging throughout the world.

According to the author, contemporary liberal education is commonly associated to the US liberal arts colleges but is also present in some American research universities. She observes that although the emergency of contemporary liberal education in the US dates from end of the $19^{\text {th }}$ century, its diffusion as a global phenomenon is recent dating from the 2000s with the emergency of liberal education in Russia, India, Israel, Nederland's, Chile, Bangladesh and Brazil. ${ }^{1 .}$

According to the GLEI, liberal education is

(1)interdisciplinary providing a broad knowledge base from social science, humanities, and natural/physical science; (2) includes a "general education" protocol, courses or curriculum required for all students in a program; and (3) emphasizes at least two of the following: transferable skills-written and oral communication, analysis and synthesis, problem solving, information and quantitative literacy, reasoning or logic, critical thinking, creativity, etc., citizenship/social responsibility/ethics, global competence, and/or studentcenteredness and holistic student development. (Godwin, 2015, p. 2)

Liberal education differs from the organization format consolidated as norm for studies in higher education: specialized curriculum, carrier focused with professionalizing studies support and utilitarian philosophy (Godwin, 2015). In other words, liberal education opposes the idea of early professionalization - it envisages culture and the expressions of truth as development basis before looking for professionalization. At the same time, its focus in transferable skills results in higher adaptability to the changing needs of a constant changing society and to the instability context in working and jobs relations that emerges from the neoliberal conjuncture. Hence, it rises as an alternative to curriculum organization in the contemporary world.

\footnotetext{
${ }^{1}$ Liberal education is present in 58 countries in five continents, divided as follows: Asia 37\%, Europe 32\%, Middle East 9\%, Latin America, $4 \%$, Oceania 4\% e Africa 2\%. In North America, Canada has 21 programs. The years of 2000 are emblematic regarding liberal education expansion: 44\% of the courses have been founded since then. Furthermore, after this date public initiatives have overtaken privates by $20 \%$. However, according to Godwin (2015) although the expansion is a tendency there are implementation difficulties of liberal education. The phenomenon occurs on the peripheral area, not influencing the traditional education system: only $2 \%$ of the countries that possess liberal education have more than 10 courses. The percentage dilution in face of the massive number of traditional initiatives hardens a higher influence of liberal education over its own valorization (Godwin, 2015, pp. 2-3).
} 


\section{Traditional models of higher education in Brazil}

In the past few years, Brazil has advanced important steps regarding higher education. Gomes and Moraes (2012) show that from 2002 the country surpassed the figure of $15 \%$ of the enrolled population, which, according to Trow (2005) indicates the shift from an elite System to a Mass System. However, the hegemonic university models did not follow global tendencies and emphasize an anachronistic, fragmentary view, with focus in monodisciplinary careers. The bibliographical review of Sguissardi (2005) and Paula (2008), pointed that the French, German and American models have led the historical development of modern university, structured Brazilian university experiences and been promoting, respectively, technical/professional formation, humanistic, scientific, integral formation and superior formation with adequacy to the market demands.

According to Paula (2008), first higher education experiences in Brazil were funded in 1908 for the Portuguese cohort over the influence of the French model. She identifies an influence of the German model in the foundation of the University of São Paulo in the 1930s during the first republican era. As well, as notices that the university reform of 1968, during the military era, brought it close to the American model.

Since them, Brazilian University has consolidated its triple function of teaching, research and extension. The idea of education has been associated to that of merchandise: the existence of a linear bind between education and economic development and working market, has been promoted, as well as stimuli for partnerships between university and the productive sector. Because of it, there was certain expansion of higher education; the principles of unified selection were established, as well as the cycle's regime, short-term courses, and the consolidation of the academic career. However, the German ideal of integral, humanistic and uninterested formation has been substituted by the instrumental rationalization and fragmentation of the intellectual work (Paula, 2008, pp.75-76).

For the author, since the 1980s, in the neoliberal economic political context,

(...)The American model has become hegemonic. We watch a 'mcdonaldization' of schooling mostly in the private sphere. A banalization of higher education to attend the demands of the job market and of clients in search for a university degree. (Paula, 2009, p.78)

In this context, questions about productivity of universities and the quality, efficiency and effectiveness of teaching developed in them gain prominence. Despite the positive aspects, the commercial logic of serial reproduction and the fragmentary form of organization have led to the graduation of professionals with unilateral profiles that are not totally prepared for the contemporary world demands and for those of the market job. 
The finding of the problem, as Jansen (1997) points out, requires rethinking the role of university. According to the author, the fragmentation of school organization refers to the nineteenth century, when school structures attended demands of the industrial society. For him, this model did not follow structural changes of information society and needs revision. The digital-cognitive society results in multiplicity, confluences, and synchronicities, produces new realities and brings new demands requiring new individual and collective attributes. New collaborative structures sustain network organization claiming up for the development of new social forms of creating knowledge and new manners of dealing with information. In this context, educators must not only keep and transmit information but also favor the development of adequate competences and skills for this context: to access, extract, interpret information, stablish connections in order to produce knowledge, adapt and create.

Based on his findings and considering the perspective defended by Danish Professor Lars Qvortup, Berg (2012) highlights the need of developing learning competences (the ability to learn and continuously re-significate their own learning). Communication competences (essential for social collaboration: capacity to communicate, selecting what is pertinent and in a given situation and being able to understand the point of view of other cultures) and formulation competences (ability to observe latent values that have not yet been outsourced and which, therefore, involve thinking, relationships and forming opinions skills). Thus, transformation must involve structures modernization in the whole educational system: it becomes necessary to update forms of action, organization, purposes and the educational models themselves, seek for greater dialogue, interaction, traffic, interdisciplinarity and the development of competences for a more autonomous learning.

\section{New university}

Proposal of Santos and Filho (2008) the project "Universidade Nova” (New University), intends to restructure Brazilian university. It points to an organization model, which is based on the cycle's formation scheme that intends to fix following problems analyzed by the authors:

1. Excessive precocity in choosing a professional carrier; 2. Limited, punctual and traumatic selection in graduation; 3. Monodisciplinary view in graduation, with narrow and retrograde curriculums; 4 , Huge gap between graduation and postgraduation; 5. Submission to the market, loss of autonomy; 6. Almost complete incompatibility with other academic models architecture currently in use in other universities realities, specially those from developed countries; 7. Non-culture: technological/professional formation, when efficient, culturally poor; 8. Anachronism: dissonance from the contemporary conjuncture or university. (p.157).

This leads to the following outspread: 
To introduce in higher education relevant themes of contemporary culture, which, considering the multicultural diversity of the current world, means, think in cultures, in plural; Endow higher education with mobility, flexibility, efficiency and quality, targeting compatibilization to the demands of higher education on the contemporary world. (Santos \& Filho, 2008, p. 199-200).

The proposed curricular structure intends to implement a three-cycle system of university education: general education (pre-graduation), specific training (undergraduate studies), and specialized professional training (postgraduate studies). The first cycle provides general training in a modality of courses called Interdisciplinary Baccalaureates (IB), which goes through the areas of scientific, technological, artistic and cultural production and is a prerequisite for the next cycles. The Second Cycle contemplates specific, professional training, with a concentrated curriculum. The third cycle corresponds to post-graduation in professional or academic category and at masters and doctoral level.

The cycle regime is compatible with the contemporary international model, with the North American (Harvard) and the European unified model (Bologna Process). However, although there are similarities, the model designed for the Brazilian reality seeks to contribute to the national identity. For the authors, the main differences between the processes are that the US pre-graduation is longer and more dense, requiring exclusive dedication. On the other hand, the Bologna Process presents, in many early cycles, very specialized curriculum structures unlike the idea of interdisciplinarity proposed here. (Santos \& Filho, 2008, pp.231-238).

Interdisciplinary Baccalaureates are composed by a set of specific areas encompassed in a previously defined larger group, such as IB in Arts, IB in Humanity, IB in Science and Technology, IB in Health. In the first cycle, IB has a common structure for all students, but each student may choose a distinct Concentration Area (CA) where develops targeted studies. Blocks and Curricular Axes in modules (courses, disciplines, activities, programs, and oriented work) are also part of it. Thus, it allows student mobility through departments and disciplines, favoring the development of broad knowledge and deep skills in an area of knowledge. (Santos \& Filho, 2008, p.202).

The scheme estimates the completion of the first cycle in 3 years with a total working load of at least 2,400 hours. The choice of a Concentration Area happens from the 4th semester of the course. Once it is completed the student has a range of options: he can complete his training in technological courses from two to three semesters, take the selection exam for the second cycle in specific education degrees (to be completed in another 1 or 2 years), or in professionals careers (from 2 to 4 years). It is also possible to apply for masters and direct doctorates, dependent on curricular evaluations.

The proposal also indicates a better articulation between undergraduate and graduate studies and allows the student to take subjects at different levels. Researcher formation gains more 
autonomy because it can happen in parallel with professional formation. That way, research is developed with emphasis, from pre-graduation. At the same time, post-graduation opens the possibility of master's degrees and professional doctorates, as in international models, surpassing the paradigm of professionalizing post-graduations and specializations that exist as alternative to high-level professional education in the hegemonic system (Santos \& Filho, 2008, p.233). ${ }^{2}$

\section{Final considerations}

Throughout this paper, we argued that liberal education presents a structure that contributes to the modernization and reorganization of universities in the contemporary scenario. Relating this structure and the skills developed on them with the social, political, economic and cultural demands that emerge from the neoliberal conjuncture, we understand the existence of forces that propel liberal education as a trend for the area. At the same time, as it promotes a paradigm shift and adaptability it can favor the development of different educational proposals, adequate to different realities.

When analyzing "New University" proposed in Brazil, we highlighted that it emphasizes the importance of a propaedeutic stage with combined studies of different areas from social science, humanities, and natural/physical science together with the possibility of research development from the earlier stages of higher education. Thus, it recovers part of the German ideal of humanistic formation. However, the philosophical base behind it results from the evolution of the postcolonial and de-colonial thinking that has valued other non-Eurocentric epistemologies and interdisciplinary/transdisciplinary work proposals. These proposals seek to achieve through an "ecology of knowledges" (Santos \& Filho, 2008), an integral, holistic formation of the individual, with the valorization and equalization of local and regional cultures to the formal and traditional ones. Thus, it can lead to the implementation of a multicultural and multi-epistemic perspective overcoming fragmentary, disciplinary views and with the proposition of new ways of conceiving training, studying, teaching and research.

Concerning the study of the arts, the propaedeutic stage allows interdisciplinary studies. It is possible to think from it, the structuring of a "basic cycle of arts", a preparatory stage in which studies are carried out in various artistic areas: dance, music, theater, visual arts, literature, film and audiovisual. This propaedeutic stage can promote a generalist formation in the field of arts and contribute to the resolution of the complex problems projected over university currently. It may favor the promotion of multiple, plural education that values different cultures, including those local and non-hegemonic ones that have historically been excluded from higher education art studies.

\footnotetext{
${ }^{2}$ It is worth noting that in the traditional system masters and doctorates are academic and work as preparatory steps for the academic career.
} 
Obviously, the propaedeutic stage opens doors for future development, but does not exempt the realization of deep studies in specific areas. After the basic cycle, the second cycle promotes specialization in one of the areas that compose it, leading to artistic or educational careers in arts. In addition, the third cycle, postgraduate, promotes research and development of artistic projects and products (books, records, DVDs, games, methods, etc.) as well as specific training for higher education professors.

Regarding pedagogical possibilities, the ecological and multi-epistemic idea favors an expansion of teaching-learning possibilities in music and arts which detailing constitutes a later stage of this research. So far, we understand that through this process it is possible to create spaces of experimentation in which one can combine practical studies with the systematized ones, promoting both the intuitive and the rational knowledge, aiming at reaching the artistic, the transcendental. Edification of spaces for involvement, performance and interdisciplinary collective creation. Spaces where are possible to promote more than technical studies aimed at producing / reproducing artistic works, but an integrated system of shared and meaningful learning about different segments of the artistic culture.

Finally, following the idea of interconnection between cycles presented before, we understand that such proposals may favor greater artistic and pedagogical development: collective experiences, artistic experimentation, development of techniques and projects, assembly of spectacles and collaborative learning relationships. Thus, it is possible to constitute a space for artistic development, research and teaching practice in a broader way, with which we seek to contribute here and which, we believe, demands a constant process of collective construction.

\section{Acknowledgment}

This study was financed in part by the Coordenação de Aperfeiçoamento de Pessoal de Nível Superior - Brazil (CAPES) - Finance Code 001

\section{References}

Berg, S. M. P. C. (2012) Estratégias de ensino e ferramentas de pedagógicas segundo os modelos propostos por Jansen e Qvortup. [Teaching Strategies and pedagogical tools according to the models proposed by Jansen and Qvortup] In: Memorandum: memória e $\begin{array}{lllll}\text { história em } & \text { psicologia, 23, 228-235. }\end{array}$ https://periodicos.ufmg.br/index.php/memorandum/issue/view/363

Godwin, K. (2015) The worldwide emergence of liberal education. International Higher education, 79, $\quad$ pp. 2-4 https://www.academia.edu/8350842/Worldwide_Emergence_of_Liberal_Education. 
Gomes, A. M., \& MORAES, K. N. (2012) Educação superior no Brasil contemporâneo: transição para um sistema de massa. [Higher Education in contemporary Brazil: transition to a mass' system] Educação \& Sociedade. 33 (118) pp. 171-190. http://dx.doi.org/10.1590/S0101-73302012000100011

Jansen, T. B. (1997) Skolens fremtider: selskabet for fremtidsforskning fremad. [The future of school: the company for future research]

Paula, M. F. (2009) A formação universitária no Brasil: concepções e influências. [University education in Brazil: concepts and influences] Avaliação, (Campinas); 14 (1), pp. 71-84. http://dx.doi.org/10.1590/S1414-40772009000100005.

Santos, B. S., \& FILHO, N. A. (2008) A universidade no século XXI: por uma universidade nova. [University on the 21st century: for a new university] Coimbra, Portugal.

Sguissardi, V. (2006) Universidade no Brasil: dos modelos clássicos aos modelos de ocasião. [University in Brazil: from classic to occasion models] In: A universidade no Brasil: concepções e modelos. Morosini, M (org) Brasília, Inep pp. 275-289. http://portal.inep.gov.br/documents/186968/484184/A+universidade+no+Brasil+concep \%C3\%A7\%C3\%B5es+e+modelos/136bcd85-aa8d-4b5c-83edd1c8d52c97a3?version=1.0

Trow, M. A. (2005) Reflections on the Transition from Elite to Mass to Universal Access: Forms and Phases of Higher Education in Modern Societies since WWII. http://repositories.cdlib.org/igs/WP2005-4. 